\title{
Uso de substratos orgânico-minerais na produção de mudas de Erythrina velutina
}

Mychelle Karla Teixeira de Oliveira ${ }^{1 *}$, Jeferson Luiz Dallabona Dombroski ${ }^{1}$, Rita de Cássia Araújo de Medeiros ${ }^{1}$, Raul Martins de Farias ${ }^{1}$, Valmor Elias Tomczak ${ }^{1}$

${ }^{1}$ Universidade Federal Rural do Semi-Árido, Departamento de Ciências Vegetais, Av. Francisco Mota, 572, CEP 59.625-900, Mossoró, RN, Brasil

\section{*Autor correspondente:}

mymykar@gmail.com

Termos para indexação:

Biomassa

Ecofisiologia

Revegetação

Index terms:

Biomass

Ecophysiology

Revegetation

Recebido em 05/09/2015

Aprovado em 10/08/2017

Publicado em 29/09/2017

doi: 10.4336/2017.pfb.37.91.1029
Resumo - O objetivo desse trabalho foi avaliar substratos orgânico-minerais na produção de mudas de Erythrina velutina Willd. Foi utilizado o delineamento inteiramente casualizado, com parcelas subdivididas no tempo, com 10 repetições. Utilizaram-se cinco substratos $(\mathrm{S})$, sendo $\mathrm{S} 1=$ solo; $\mathrm{S} 2=$ solo + esterco bovino curtido $(20 \%) ; \mathrm{S} 3=$ solo + superfosfato simples $\left(300 \mathrm{~g} \mathrm{~m}^{-3}\right) ; \mathrm{S} 4=$ solo + superfosfato simples + micronutrientes $\left(300 \mathrm{~g} \mathrm{~m}^{-3}, 50 \mathrm{~g} \mathrm{~m}^{-3}\right) ; \mathrm{S} 5=$ solo + superfosfato simples + micronutrientes $\left(300 \mathrm{~g} \mathrm{~m}^{-3}, 50 \mathrm{~g} \mathrm{~m}^{-3}\right)+$ esterco bovino curtido. O substrato foi composto de solo e esterco bovino curtido na proporção 4:1, de acordo com cada tratamento. As coletas de mudas foram realizadas em intervalos de 14, 28, 42, 56 e 70 dias após semeadura. As variáveis analisadas foram: comprimento da parte aérea, número de folhas, diâmetro de coleto, área foliar, massa seca de caule, de folhas, da parte aérea, das raízes, total e relação massa seca da parte aérea e das raízes. Houve efeito significativo dos substratos orgânico-minerais para as variáveis analisadas. O substrato composto por solo com adição de superfosfato simples $\left(300 \mathrm{~g} \mathrm{~m}^{-3}\right)$, micronutrientes $\left(50 \mathrm{~g} \mathrm{~m}^{-3}\right)$ e $20 \%$ de esterco bovino curtido é indicado para produção de mudas de Erythrina velutina.

\section{Use of organic-mineral substrates to produce seedlings of Erythrina velutina}

\begin{abstract}
The aim of this work was to evaluate organic-mineral substrates in the production of Erythrina velutina seedlings. The experiment was conducted in a split-plot completely randomized design, subdivided in time, with 10 replications. Five substrates (S) were used: $\mathrm{S} 1=$ soil; S2 = soil + tanned bovine manure $(20 \%)$; S3 = soil + simple superphosphate $\left(300 \mathrm{~g} \mathrm{~m}^{-3}\right) ; \mathrm{S} 4=$ soil + simple superphosphate + micronutrients $(300$ $\left.\mathrm{g} \mathrm{m}^{-3}, 50 \mathrm{~g} \mathrm{~m}^{-3}\right) ; \mathrm{S} 5=$ soil + simple superphosphate + micronutrients $\left(300 \mathrm{~g} \mathrm{~m}^{-3}, 50 \mathrm{~g}\right.$ $\left.\mathrm{m}^{-3}\right)+$ tanned bovine manure. The substrate was composed of soil, and bovine manure tanned in the ratio $4: 1$, according to each treatment. Five seedlings were collected at intervals of 14, 28, 42, 56 and 70 days after sowing. The analyzed variables were: shoot length, number of leaves, collar diameter, leaf area, stem, leaves, shoots, roots and total dry mass, and shoot and roots dry mass ratio. The analyzed variables showed significant effect with the organic-mineral substrates. The substrate composed of soil with simple superphosphate $\left(300 \mathrm{~g} \mathrm{~m}^{-3}\right)$, micronutrients $\left(50 \mathrm{~g} \mathrm{~m}^{-3}\right)$ and $20 \%$ of tanned bovine manure is indicate to produce Erythrina velutina seedlings.
\end{abstract}




\section{Introdução}

A produção de mudas é uma das etapas mais importantes em projetos de reflorestamento, com demanda crescente em programas de gestão ambiental, sendo usada a regeneração artificial pelo plantio de mudas e/ou semeadura direta. Erythrina velutina Willd., conhecida como bucaré, mulungu, mulunguda-flor-vermelha, entre outros nomes, é uma espécie arbórea com grande potencial para reflorestamento, pois apresenta características importantes, como rusticidade, tolerância à seca, rápido crescimento e capacidade de fixação de nitrogênio atmosférico (Holanda et al., 2010; Santos et al., 2012).

Para a produção de mudas se faz necessário o uso de substratos de qualidade, devendo este apresentar boa capacidade de retenção de água, porosidade, teor nutricional e capacidade de troca de cátions. $\mathrm{O}$ baixo custo e a disponibilidade nas proximidades da região de consumo são também características importantes. Vários materiais têm sido estudados como substratos para produção de mudas de diferentes espécies florestais, como mistura de areia com vermiculita (Alves et al., 2008; Guimarães et al., 2011) e vermiculita + casca de arroz carbonizada para Copaifera langsdorffii (Dutra et al., 2012), terra + areia + adubo para Caesalpinia ferrea (Scalon et al., 2011), 40\% de esterco bovino + $60 \%$ de serragem para Ilex paraguariensis (Wendling et al., 2007), e composto vegetal para Cedrela odorata (Rowedwer et al., 2012).

A adição de uma fonte orgânica de nutrientes pode influenciar o acúmulo de massa seca total, porque esta fonte orgânica adicionada ao solo proporciona maior retenção de água, melhora a aeração das raízes e disponibiliza nutrientes para a muda (Araújo \& Paiva Sobrinho, 2011). Na produção de mudas de Enterolobium contortisiliquum, os autores observaram que a presença de matéria orgânica nos substratos evidencia sua importância para a formação das mudas (Araújo \& Paiva Sobrinho, 2011).

Apesar do potencial de Erythrina velutina para reflorestamento ou outros fins, esta espécie ainda é pouca estudada. Neste contexto, objetivou-se com este trabalho avaliar substratos orgânico-minerais na produção de mudas de Erythrina velutina.

\section{Material e métodos}

O experimento foi desenvolvido no viveiro de produção de mudas localizado na área experimental do Departamento de Ciências Vegetais da Universidade Federal Rural do Semi-Árido, UFERSA, em Mossoró, RN (5'12'16,4"'S e $37^{\circ} 19^{\prime} 25,7^{\prime}$ 'W e altitude média de $18 \mathrm{~m})$.

O clima local, segundo Thornthwaite, é classificado como DdAa', ou seja, semiárido, megatérmico e com pequeno ou nenhum excesso de água durante o ano. De acordo com Köppen é BSwh', equivalente a clima seco e muito quente, com duas estações climáticas bem definidas, sendo uma seca, que geralmente compreende o período de junho a janeiro, e uma chuvosa, entre os meses de fevereiro e maio (Carmo Filho et al., 1991).

Foi utilizado o delineamento inteiramente casualizado (DIC), com parcelas subdivididas no tempo, com 10 repetições. Utilizaram-se cinco substratos (S), sendo S1 $=$ solo; $\mathrm{S} 2=$ solo + esterco bovino curtido $(20 \%) ; \mathrm{S} 3$ $=$ solo + superfosfato simples $\left(300 \mathrm{~g} \mathrm{~m}^{-3}\right) ; \mathrm{S} 4=$ solo + superfosfato simples + micronutrientes $\left(300 \mathrm{~g} \mathrm{~m}^{-3}, 50 \mathrm{~g}\right.$ $\mathrm{m}^{-3}$, respectivamente); $\mathrm{S} 5=$ solo + superfosfato simples + micronutrientes $\left(300 \mathrm{~g} \mathrm{~m}^{-3}, 50 \mathrm{~g} \mathrm{~m}^{-3}\right.$, respectivamente) + esterco bovino curtido. Preencheram-se sacos plásticos com 1,5 L de volume. O substrato foi composto de solo argilo-arenoso (Neossolo Quartzarênico), e esterco bovino curtido na proporção 4:1, de acordo com cada tratamento.

Após a coleta, as sementes foram beneficiadas manualmente no Laboratório de Análise de Sementes da UFERSA, descartando-se aquelas que estavam chochas ou danificadas por insetos. Realizou-se o tratamento para a superação da dormência pelo método da escarificação mecânica, provocando ruptura do tegumento na extremidade da semente próxima à região da emissão da radícula, pela fricção com lixa. Em seguida, realizouse a semeadura, de acordo com cada tratameno, na profundidade de 2 a $3 \mathrm{~cm}$, tomando-se o cuidado para colocar as sementes posicionadas com o hilo para baixo (Matheus et al., 2010). Antes da semeadura, retirou-se amostra de cada substrato para caracterização química (Tabela 1). 
Tabela 1. Dados da análise química dos substratos utilizados no estudo de emergência e desenvolvimento de mudas antes da semeadura.

\begin{tabular}{|c|c|c|c|c|c|c|}
\hline \multirow[t]{2}{*}{ Elementos } & \multirow[t]{2}{*}{ Unidade } & \multicolumn{5}{|c|}{ Substratos } \\
\hline & & S1 & S2 & S3 & S4 & S5 \\
\hline $\mathrm{pH}$ & em água & 7,05 & 7,65 & 7,95 & 7,33 & 7,50 \\
\hline $\mathrm{CE}$ & $\mathrm{dS} \mathrm{m}^{-1}$ & 0,08 & 0,59 & 0,32 & 0,09 & 0,08 \\
\hline $\mathrm{N}$ & $\%$ & 3,00 & 3,80 & 3,60 & 3,50 & 3,70 \\
\hline $\mathrm{P}$ & $\mathrm{mg} \mathrm{dm}{ }^{-3}$ & 0,13 & 0,21 & 0,18 & 0,19 & 0,18 \\
\hline K & $\mathrm{mg} \mathrm{dm}{ }^{-3}$ & 4,10 & 6,70 & 3,60 & 4,60 & 4,90 \\
\hline $\mathrm{Na}$ & $\mathrm{mg} \mathrm{dm}{ }^{-3}$ & 0,31 & 0,54 & 0,55 & 0,28 & 0,38 \\
\hline $\mathrm{Ca}$ & cmolc $\mathrm{dm}^{3}$ & 9,60 & 9,01 & 6,80 & 2,89 & 3,20 \\
\hline $\mathrm{Ca}+\mathrm{Mg}$ & cmolc dm ${ }^{-3}$ & 13,26 & 12,23 & 8,58 & 5,56 & 4,67 \\
\hline $\mathrm{Al}$ & cmolc dm ${ }^{-3}$ & 0,10 & 0,05 & 0,05 & 0,10 & 0,10 \\
\hline $\mathrm{Fe}$ & $\mathrm{mg} \mathrm{kg}^{-1}$ & 0,47 & 0,97 & 0,95 & 0,56 & 0,57 \\
\hline $\mathrm{Zn}$ & $\mathrm{mg} \mathrm{kg}^{-1}$ & 0,31 & 0,54 & 0,55 & 0,28 & 0,38 \\
\hline $\mathrm{Cu}$ & $\mathrm{mg} \mathrm{kg}^{-1}$ & 0,21 & 0,38 & 0,64 & 0,54 & 0,49 \\
\hline $\mathrm{Mn}$ & $\mathrm{mg} \mathrm{kg}^{-1} \mathrm{~g}$ & 0,31 & 0,54 & 0,55 & 0,28 & 0,38 \\
\hline $\mathrm{MO}$ & $\mathrm{g} \mathrm{kg}^{-1}$ & 7,10 & 16,40 & 13,00 & 11,00 & 16,00 \\
\hline
\end{tabular}

O experimento foi conduzido em casa de vegetação, com cobertura e paredes laterais de telado com $50 \%$ de sombreamento. No teto da casa de vegetação foi instalado o sistema de irrigação por microaspersão, utilizado para realização de duas irrigações diárias (manhã e final da tarde).

$\mathrm{O}$ crescimento das mudas foi analisado em cinco coletas de plantas $(14,28,42,56$ e 70 dias após semeadura). O intervalo para coleta de dados foi definido de acordo com a morfologia própria da espécie, que apresenta emergência e crescimento rápidos. As raízes foram lavadas para retirada de restos de substrato, após a retirada das mudas dos sacos plásticos. As variáveis analisadas foram: comprimento da parte aérea (CPA), número de folhas (NF), diâmetro de coleto (DC), área foliar (AF), massa seca de caule (MSC), massa seca de folhas (MSF), massa seca da parte aérea (MSPA), massa seca das raízes (MSR), relação massa seca da parte aérea e raízes (MSPR) e massa seca total (MST).

O comprimento da parte aérea foi mensurado utilizando régua graduada, medindo-se do coleto até o ápice. $\mathrm{O}$ diâmetro do coleto foi determinado com paquímetro digital $(0,01 \mathrm{~mm})$. A área foliar foi determinada de forma destrutiva, utilizando a metodologia de discos foliares (Fernandes, 2000). Após essas avaliações, as mudas foram fracionadas em caule, folhas e raízes e, em seguidas, foram aconcionadas em sacos de papel e postas para secagem em estufa com circulação forçada de ar, com temperatura de $65^{\circ} \mathrm{C}$, até atingir massa constante. Após a secagem, determinaramse as massas das diferentes partes das plantas, utilizando uma balança analítica $(0,01 \mathrm{~g})$. Em seguida, determinouse a masa seca total (caule + folhas + raízes), bem como a relação entre massa seca de parte aérea e das raízes.

Os dados foram analisados por análise de variância pelo teste $\mathrm{F}$ e as médias, referentes aos acessos e substratos, foram comparadas pelo teste de Tukey a 5\% de probabilidade. Ajustaram-se equações de regressão para avaliar o crescimento das plantas ao longo do experimento, utilizando as épocas de coleta como variáveis independentes. As análises estatísticas foram realizadas com o uso do programa estatístico SISVAR (Ferreira, 2011).

\section{Resultados e discussão}

Houve efeito significativo positivo dos substratos orgânico-minerais para as variáveis analisadas: 
comprimento da parte aérea (CPA), número de folhas (NF), diâmetro de coleto (DC), área foliar (AF), massa seca de caule (MSC), massa seca de folhas (MSF), massa seca da parte aérea (MSPA), massa seca das raízes (MSR), relação massa seca da parte aérea e das raízes (MSPR) e massa seca total (MST), aos 56 e 70 dias após a semeadura (DAS). Em estudo desenvolvido por Araújo \& Paiva Sobrinho (2011) em mudas de Enterolobium contortisiliquum foi observado efeito positivo da adição de matéria orgânica ao substrato para a produção de mudas desta espécie.

O CPA foi afetado pelos substratos, sendo a diferença mais expressiva entre $\mathrm{S} 5$ e $\mathrm{S} 1$, com o primeiro superior em 8,$17 ; 13,09$ e $11,82 \%$ nas avaliações realizadas aos 42, 56 e 70 DAS, respectivamente. Analisando a variável CPA em função das épocas de avaliação, foi observado comportamento polinomial ao longo do experimento, em que valores máximos foram obtidos aos $70 \mathrm{DAS}$, sendo: 32,$86 ; 39,43 ; 37,47 ; 37,37$ e $42,43 \mathrm{~cm}$, para substratos (S1), (S2), (S3), (S4) e (S5), respectivamente (Figura 1a).
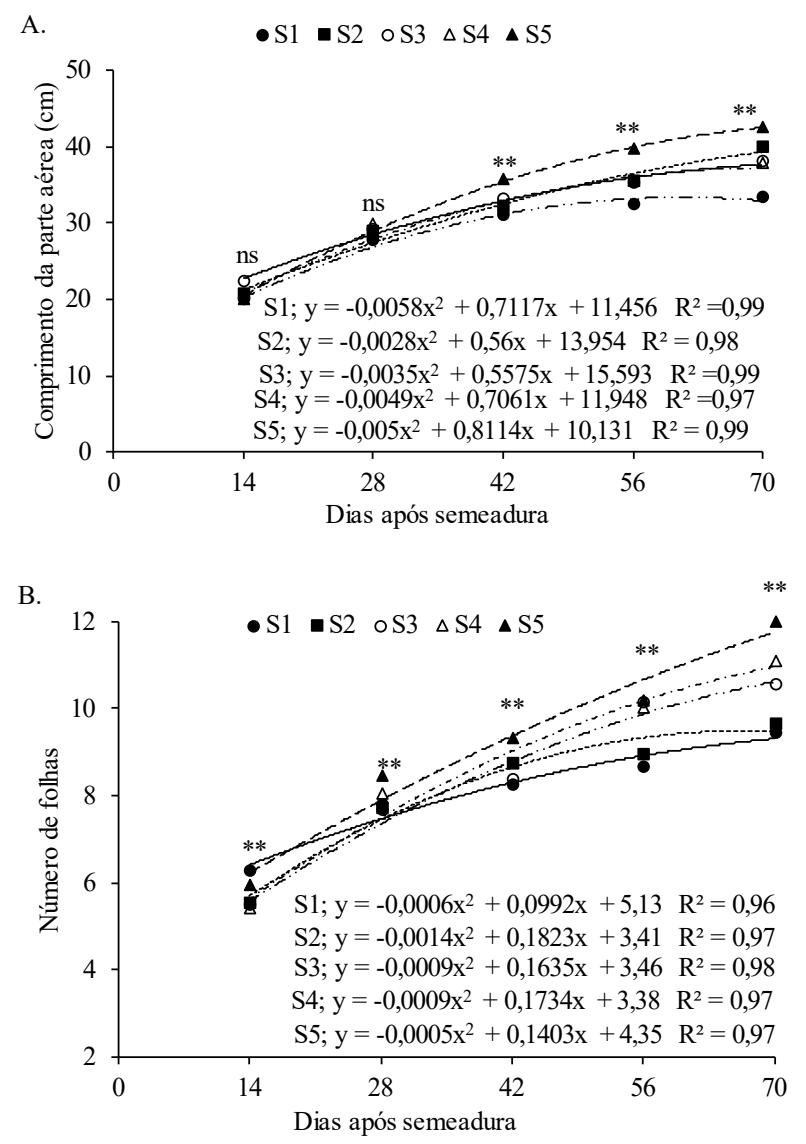

Figura 1. Comprimento da parte aérea $(\mathrm{A})$ e número de folhas (B) de mudas de Erythrina velutina em substratos orgânicominerais.
Houve diferença significativa entre os substratos para número de folhas (NF), pois o substrato S5 apresentou valores superiores em comparação ao substrato $\mathrm{S} 1$, com maior incremento em número de folhas, com percentuais de 8,$33 ; 12,73 ; 17,92$ e $26,98 \%$, aos $28,42,56$ e 70 DAS, respectivamente. O comportamento polinomial foi observado, sendo os valores estimados entre 9 e 12 folhas por planta, aos 70 DAS (Figura 1b).

Essa superioridade do substrato $\mathrm{S} 5$ em relação ao S1, possivelmente, ocorre em decorrência da maior disponibilidade de nutrientes, especialmente fósforo e nitrogênio, este último proveniente da matéria orgânica (Tabela 1). Resposta positiva da adubação fosfatada na variável altura de mudas de mulungu também foi observada por Leite et al. (2014).

Efeito positivo da aplicação do esterco bovino curtido sobre o CPA também foi observado por Cunha et al. (2006) em mudas de Acacia sp., demonstrando que a presença do material orgânico é importante, por conter quantidades relevantes de nutrientes. Mesmo assim, as espécies arbóreas apresentam, em geral, grande variação de crescimento, quando considerado o comprimento da parte aérea, apresentando características de fácil adaptabilidade (Roweder et al., 2012).

O CPA destaca-se, dentre as variáveis morfológicas, como um importante atributo para se estimar a qualidade das mudas, principalmente por ser de fácil execução e por ser avaliado de forma não destrutiva (Gomes et al., 2002). De acordo com Gonçalves et al. (2005), as mudas classificadas como de bom padrão comercial devem apresentar CPA entre 20 e $35 \mathrm{~cm}$.

Desse modo, mudas de Erythrina velutina apresentam CPA satisfatório para transplantio em torno de 50 dias após semeadura. Este resultado favorece a tomada de decisão para produção de mudas mais precoces, o que aumentaria a eficiência produtiva de mudas, pois permite aumentar a quantidade produzida por área de viveiro, em menor intervalo de tempo.

Para o diâmetro de coleto (DC), verificou-se diferença significativa aos 56 e $70 \mathrm{DAS}$, em que foram observados maiores valores nos substratos S2 e S5, apresentando 12,86 e 13,69 mm, respectivamente, aos 70 DAS (Figura 2a).

O diâmetro do coleto é um indicativo de qualidade de mudas, por apresentar alta correlação com a sobrevivência pós-transplantio, além de apresentar alta capacidade de formação e de crescimento de novas raízes (Souza et al., 2006). Estima-se que mudas que 
apresentam diâmetro de coleto entre 5 e $10 \mathrm{~mm}$ estão aptas para transplantio (Gonçalves et al., 2005)

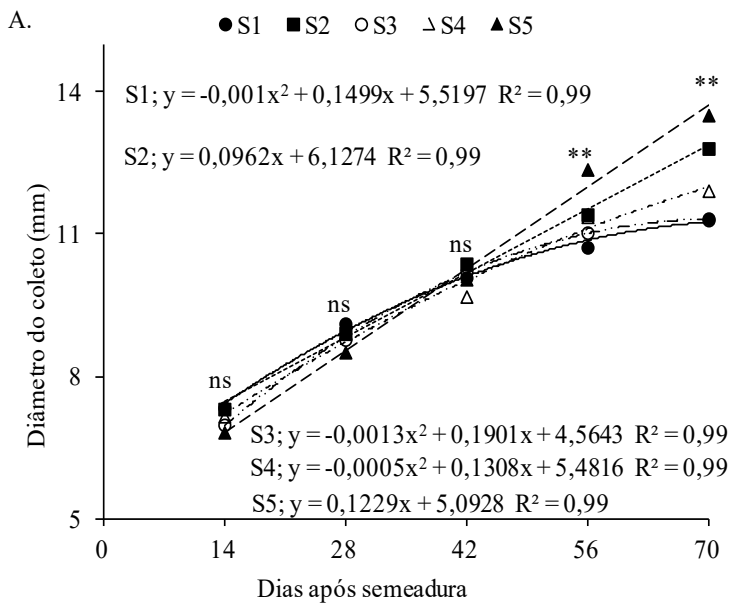

B.

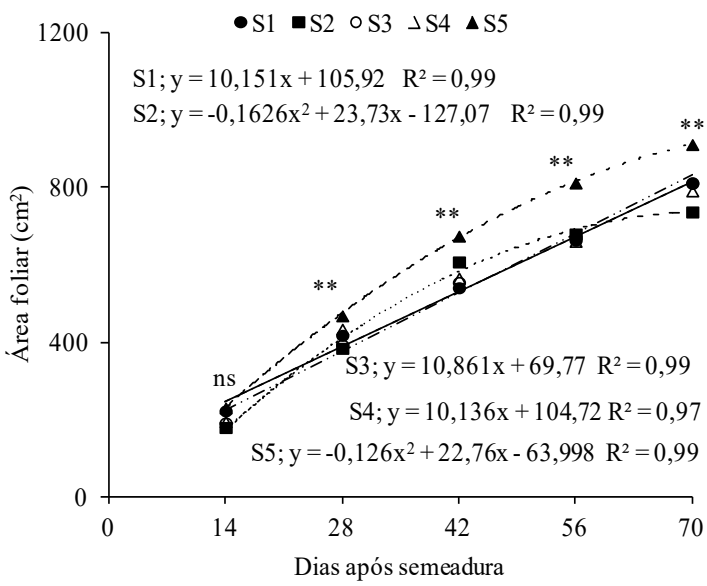

Figura 2. Diâmetro do coleto (A) e área foliar (B) de Erythrina velutina em substratos orgânico-minerais.

Foi observada diferença significativa entre substratos ao analisar a variável área foliar (AF), sendo o S5 superior ao S1, em 12,$00 ; 24,42 ; 22,24$ e $12,39 \%$, aos $28,42,56$ e 70 DAS, respectivamente. A variável AF demonstrou comportamento polinomial ao longo do experimento para todos os substratos utilizados (Figura 2b). Este resultado corrobora com os de Guimarães et al. (2011), que ao avaliarem mudas de Erythrina velutina, verificaram que os substratos constituídos de areia e composto orgânico proporcionaram maiores valores de área foliar.

A área foliar apresenta um papel fundamental na determinação da quantidade de luz que a planta intercepta, na fixação de carbono, na perda de água e até na produtividade do ecossistema (Van Volkenburgh,
1999). Esta variável tem grande importância para a avaliação da qualidade de mudas, pois a quantidade de fotoassimilados na planta é, geralmente, proporcional à área foliar, e esses são convertidos em biomassa, o que contribui para o aumento da matéria seca total (Pinto et al., 2011).

A variável massa seca de caule demonstrou diferença significativa entre substratos, sendo S5 superior em 22,28 e $22,43 \%$ ao S1, aos 56 e $70 \mathrm{DAS}$, respectivamente. No entanto, nas demais avaliações não houve diferença significativa, com valores médios de 0,87; 1,21 e 1,98 g, aos 14, 28 e 42 DAS. Ainda nesta variável, o crescimento das mudas ocorreu de forma quadrática, obtendo-se maiores valores em 4,37; 4,42; 4,44; 4,29 e 5,18 g nos substratos S1, S2, S3, S4 e S5, respectivamente, aos 70 DAS (Figura 3a).
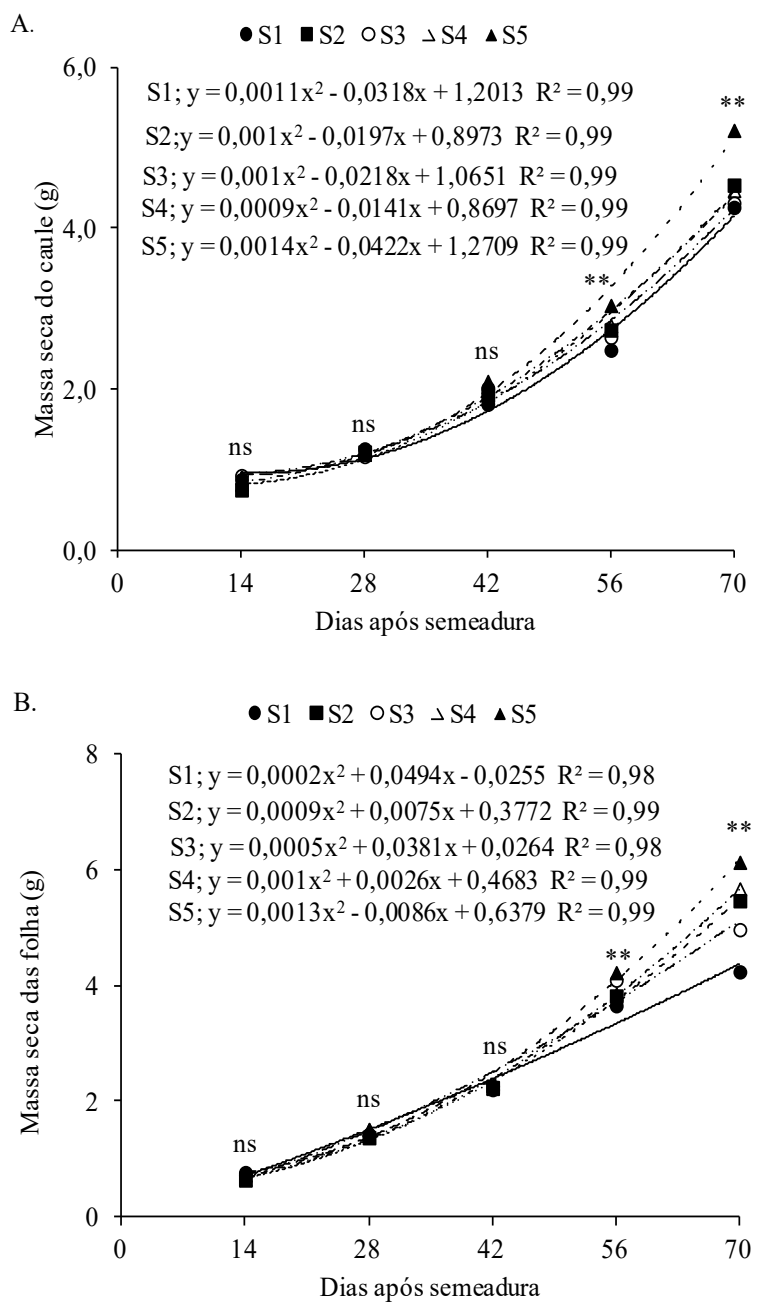

Figura 3. Massa seca do caule (A) e das folhas (B) de Erythrina velutina em substratos orgânico-minerais. 
Analisando-se a massa seca foliar, observou-se que o S5 foi superior ao S1 em 15,65 e 44,67\% aos 56 e 70 DAS, respectivamente. Verificou-se comportamento quadrático com os substratos avaliados, sendo que a diferença mais acentuada obtida entre os substratos foi aos 70 DAS $(4,41 ; 5,31 ; 5,14 ; 5,55$ e $6,41 \mathrm{~g}$, com os substratos S1, S2, S3, S4 e S5, respectivamente) (Figura 3b).

Comportamento quadrático e diferença significativa entre substratos também foram obtidos para a variável MSPA, sendo S5 superior ao S1 em 18,33 e 33,52\% aos 56 e 70 DAS, respectivamente. Os maiores valores de MSPA foram obtidos aos 70 DAS $(8,38 ; 9,73 ; 9,58$; 9,84 e 11,09 g nos substratos S1, S2, S3, S4 e S5, respectivamente) (Figura 4a).

De forma geral, ao final do experimento (70 DAS) as mudas mais vigorosas quanto ao acúmulo de massa seca na parte aérea foram obtidas em S5, enquanto o $\mathrm{S} 1$ resultou em menores valores. Além disso, verificouse que a adição de apenas esterco bovino curtido (S2) é mais benéfico que adição de apenas superfosfato simples (S3). Este comportamento pode ser atribuído ao efeito benéfico pela disponibilidade de macro e micronutrientes, bem como pela maior disponibilidade de água, favorecendo a absorção de nutrientes (Correia et al., 2001).

Foram observadas diferenças significativas entre os substratos nas avaliações de MSR realizadas aos 42, 56 e 70 DAS, com maiores valores ocorrendo no S2. Analisando-se a MSR ao longo experimento, verificouse comportamento linear em todos os substratos, de forma que os maiores valores ocorreram aos 70 DAS, com MSR máximas de 1,$07 ; 1,20 ; 1,07 ; 1,02$ e 1,10 g, para os substratos S1, S2, S3, S4 e S5, respectivamente (Figura 4b).

Resposta positiva do uso de esterco bovino sobre a produção de matéria seca também foi observada em mudas de E. contortisiliquum (Araújo \& Paiva Sobrinho, 2011), Acacia mangium e A. auriculiformes (Cunha et al., 2006). O efeito positivo da adubação orgânica sobre a produção de MSPA pode ser atribuído à melhoria na estrutura do solo, permitindo a maior absorção de nutrientes e desenvolvimento do sistema radicular (Dias et al., 2008).

O substrato com acréscimo de esterco bovino curtido provavelmente serviu como aporte ao crescimento das mudas, por fornecer nutrientes essenciais. O efeito positivo no crescimento da MSPA, se da pelas folhas serem o principal local onde ocorre a fotossíntese e também serem órgãos de reserva, fonte de auxina e cofatores de enraizamento, contribuindo ainda para a formação de novos tecidos (Hartmann et al., 1997). Além disso, o esterco é um componente orgânico que melhora as condições físicas do substrato, como aeração e drenagem, além de ser rico em nutrientes, que são rapidamente liberados para as plantas (Correia et al., 2001). Assim, o substrato exerce influência marcante na massa seca do sistema radicular e no estado nutricional das plantas, interferindo na qualidade das mudas (Roweder et al., 2012).

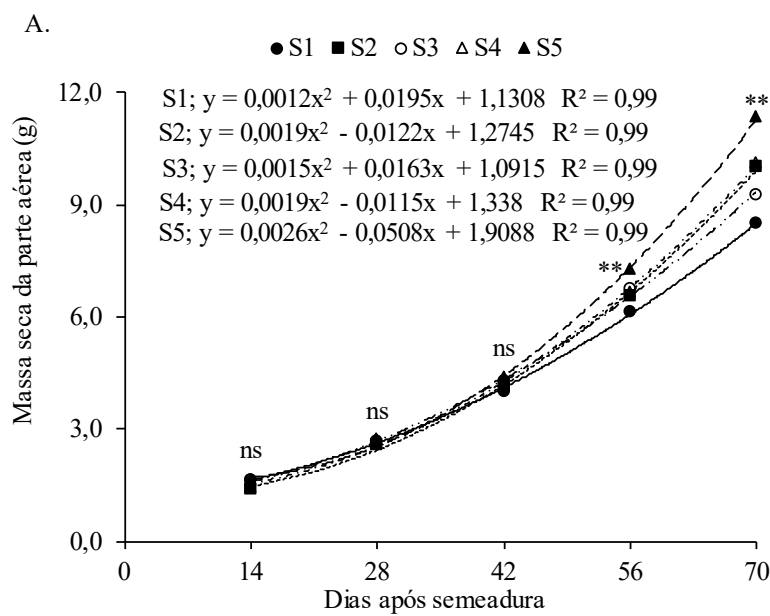

B. $\bullet \mathrm{S} 1=\mathrm{S} 2 \quad \mathrm{~S} 3 \quad \Delta \mathrm{S} 4 \Delta \mathrm{S} 5$

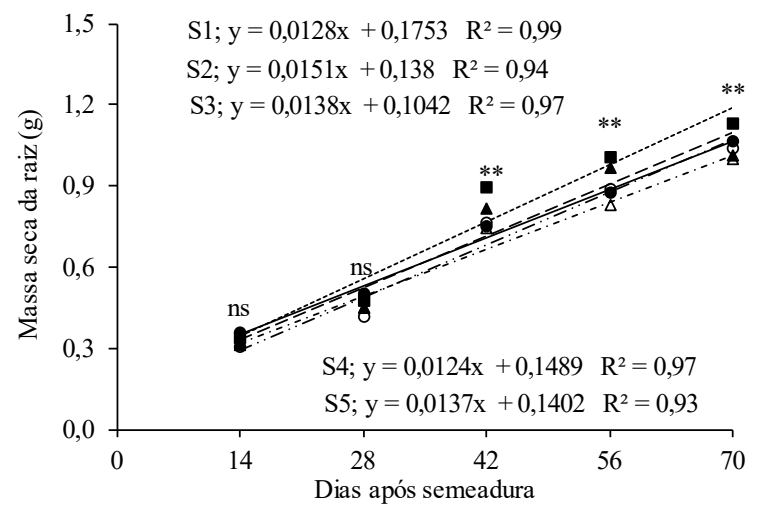

Figura 4. Massa seca da parte aérea (A) e massa seca de raízes (B) de Erythrina velutina em substratos orgânicominerais.

Pela análise da relação MSPA/MSR, verificou-se comportamento semelhante ao observado para as variáveis MSC (Figura 3a), MSF (Figura 3b) e MSPA (Figura 4a), com comportamento quadrático ao longo 
do experimento. Aos 70 DAS foram obtidos os maiores valores, com 8,40, 8,01, 9,35, 10,33 e 11,60, para $\mathrm{S} 1$, S2, S3, S4 e S5, respectivamente (Figura 5a).

É importante destacar a variável MSPA, principalmente quando as mudas são levadas para transplantio em campo, pois a parte aérea das mudas não deve ser muito superior que a das raízes, em função de problemas relacionados com absorção de água (Caldeira et al., 2008). Corrobora-se com outros autores, pois a relação de massa seca da parte aérea e raízes é uma variável que indica a qualidade das mudas, uma vez que se espera equilíbrio no desenvolvimento entre a parte aérea e o sistema radicular da planta (Campos \& Uchida, 2002).
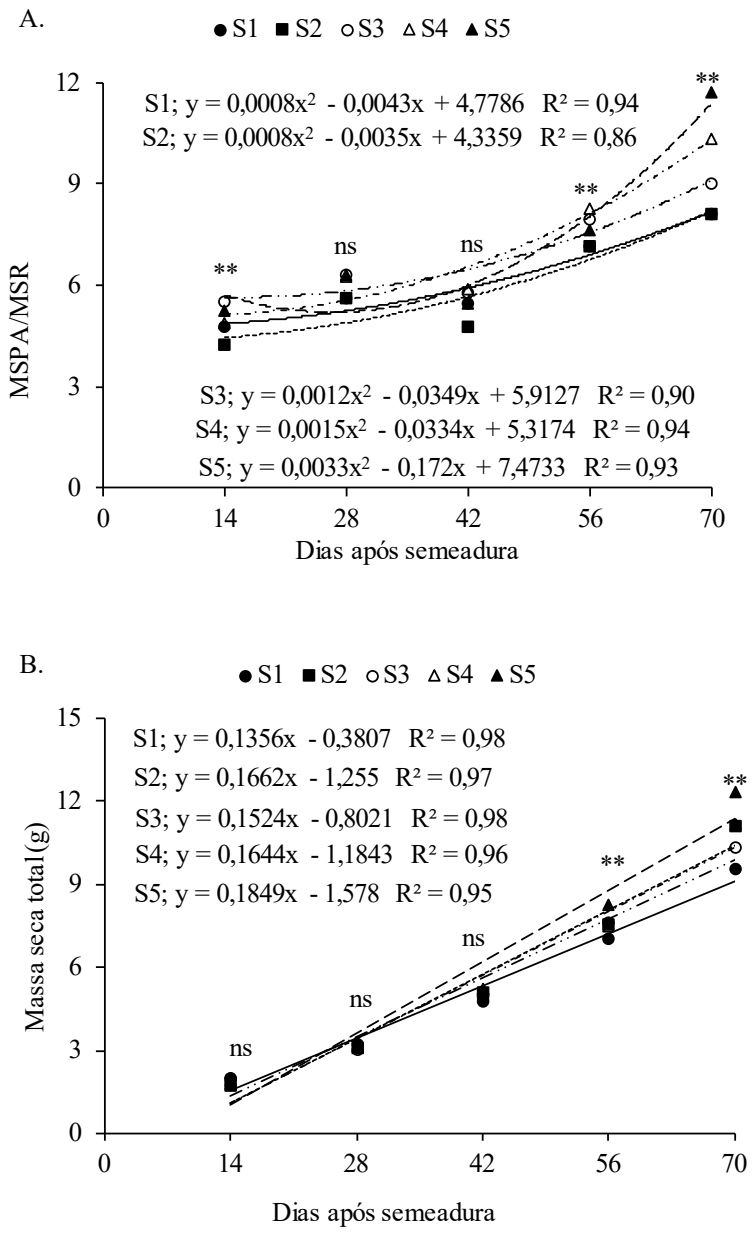

Figura 5. Relação massa seca da parte aérea e raízes (MSPA/ MSR) (A) e massa seca total (B) de Erythrina velutina em substratos orgânico-minerais.

A MST aumentou linearmente ao longo do experimento, de forma que os maiores valores foram observados aos 70 DAS, com 9,11; 10,38, 9,89, 10,32 e 11,37 g, para S1, S2, S3, S4 e S5, respectivamente. Verificou-se ainda diferença significativa entre substratos para MST, sendo S5 superior ao S1, em 17,36 e 29,27\% aos 56 e 70 dias DAS, respectivamente (Figura 5b).

Em trabalho com mudas de mulungu em diferentes substratos, Guimarães et al. (2011) verificaram que os substratos constituídos de areia e composto orgânico proporcionaram maiores valores de massa seca total. Em outras espécies arbóreas, os substratos complementados com micorriza e fósforo, para jatobá (Barbieri Júnior et al., 2007), vermiculita e casca de arroz, para copaíba (Dutra et al., 2012), e adubo orgânico, para pau-ferro (Scalon et al., 2011), proporcionaram efeito satisfatório na produção das mudas.

\section{Conclusões}

De forma geral, a adição de esterco bovino, fósforo e micronutrientes em substratos para a produção de mudas proporciona maior disponibilidade de nutrientes para as plantas, evidenciando a necessidade da elaboração de substrato enriquecido para produção de mudas de Erythrina velutina.

\section{Referências}

Alves, E. U. et al. Substratos para testes de emergência de plântulas e vigor de sementes de Erythrina velutina Willd., Fabaceae. Semina: Ciências Agrárias, v. 29, n. 1, p. 69-82, 2008. DOI: 10.5433/1679-0359.2008v29n1p69.

Araújo, A. P. \& Paiva Sobrinho, S. Germinação e produção de mudas de tamboril (Enterolobium contortisiliquum (vell.) Morong) em diferentes substratos. Revista Árvore, v. 35, n. 3, supl. 1, p. 581-588, 2011. DOI: 10.1590/S0100-67622011000400001.

Barbieri Júnior, D. et al. Análise de crescimento de Hymenaea courbaril sob efeito da inoculação micorrizica e adubação fosfatada. Revista de Ciências Agro-Ambientais, n. 1, p. 1-15, 2007

Caldeira, M. V. W. et al. Composto orgânico na produção de mudas de aroeira-vermelha. Scientia Agraria, v. 9, n. 1, p. 27-33, 2008. DOI: 10.5380/ rsa.v9i1.9898.

Campos, M. A. A. \& Uchida, T. Influência do sombreamento no crescimento de mudas de três espécies amazônicas. Pesquisa Agropecuária Brasileira, v. 37, n. 3, p. 281-288, 2002. DOI: 10.1590/S0100-204X2002000300008.

Carmo Filho, F. et al. Dados climatológicos de Mossoró: um município Semi-Árido Nordestino. Mossoró: Escola Superior de Agricultura de Mossoró, 1991. $121 \mathrm{p}$.

Correia, D. et al. Alternativas de substratos para a formação de porta enxertos de gravioleira (Annona muricata) em tubetes. Fortaleza: Embrapa Agroindústria Tropical, 2001. (Embrapa Agroindústria Tropical. Comunicado técnico, 67).

Cunha, A. M. et al. Efeito de diferentes substratos sobre o desenvolvimento de mudas de Acacia sp. Revista Árvore, v. 30, n. 2, p. 207-214, 2006. DOI: 10.1590/S0100-67622006000200007. 
Dias, M. A. et al. Germinação de sementes e desenvolvimento de plantas de pimenta malagueta em função do substrato e da lâmina de água. Revista Brasileira de Sementes, v. 30, n. 3, p. 115-121, 2008. DOI: 10.1590/S010131222008000300015 .

Dutra, T. R. et al. Desenvolvimento inicial de mudas de copaíba sob diferentes níveis de sombreamento e substratos. Revista Ciência Agronômica, v. 43, n. 2, p. 321-329, 2012. DOI: 10.1590/S1806-66902012000200015.

Fernandes, P. D. Análise de crescimento e desenvolvimento vegetal. Campina Grande: UFPB, Departamento de Engenharia Agrícola, 2000. 22 p.

Ferreira, D. F. Sisvar: um sistema computacional de análise estatística. Ciência e Agrotecnologia, v. 35, n. 6, p. 1039-1042, 2011. DOI: 10.1590/ S1413-70542011000600001

Gomes, J. M. et al. Parâmetros morfológicos na avaliação da qualidade de mudas de Eucaliptus grandis. Revista Árvore, v. 26, n. 6, p. 655-664, 2002. DOI: $10.1590 / \mathrm{S} 0100-67622002000600002$.

Gonçalves, J. L. M. et al. Produção de mudas de espécies nativas: substrato, nutrição, sombreamento e fertilização; In: Gonçalves, J. L. M. \& Benedetti, V. (Org.). Nutrição mineral de plantas. Piracicaba: IPEF, 2005. 427 p.

Guimarães, I. P. et al. Efeito de diferentes substratos na emergência e vigor de plântulas de mulungú. Bioscience Journal, v. 27, n. 6, p. 932-938, 2011.

Hartmann, H. T. et al. Plant propagation: principles and practices. 6th ed. New Jersey: Prentice Hall, 1997.

Holanda, F. S. R. et al. Crescimento inicial de espécies florestais na recomposição da mata ciliar em taludes submetidos à técnica da bioengenharia de solos. Ciência Florestal, v. 20, n. 1, p. 157-166, 2010. DOI: $10.5902 / 198050981770$.
Leite, T. S. et al. Crescimento e partição da biomassa de mudas de mulungu sob adubação fosfatada e inoculação micorrízica. Pesquisa Florestal Brasileira, v. 34, n. 80, p. 407-415, 2014. DOI: 10.4336/2014.pfb.34.80.642.

Matheus, M. T. et al. Superação da dormência em sementes de duas espécies de Erythrina. Revista Caatinga, v. 23, n. 3, p. 48-53, 2010.

Pinto, S. I. C. et al. Eficiência nutricional de clones de eucalipto na fase de mudas cultivados em solução nutritiva. Revista Brasileira de Ciência do Solo, v. 35, n. 2, p. 523-533, 2011.

Roweder, C. et al. Uso de diferentes substratos e ambiência na germinação e desenvolvimento inicial de plântulas de cedro. Revista Brasileira de Tecnologia Aplicada nas Ciências Agrárias, v. 5, n. 1, p. 27-46, 2012. DOI: 10.5777/paet.v5i1.1603.

Santos, P. L. et al. Estabelecimento de espécies florestais nativas por meio de semeadura direta para recuperação de áreas degradadas. Revista Árvore, v. 36, n. 2, p. 237-245, 2012. DOI: 10.1590/S0100-67622012000200005.

Scalon, S. P. Q. et al. Germinação e crescimento de Caesalpinia férrea MART. EX TUL. em diferentes substratos. Revista Árvore, n. 3, supl. 1, p. 633-639, 2011. DOI: $10.1590 / \mathrm{S} 0100-67622011000400007$.

Souza, C. A. M. et al. Crescimento em campo de espécies florestais em diferentes condições de adubação. Ciência Florestal, v. 16, n. 3, p. 243-249, 2006. DOI: $10.5902 / 198050981905$.

Wendling, I. et al. Características físicas e químicas de substratos para produção de mudas de Ilex paraguariensis St. Hil. Revista Árvore, v. 31, n. 2, p. 209-220, 2007. DOI: 10.1590/S0100-67622007000200003.

Van Volkenburgh, E. Leaf expansion: an integrating plant behavior. Plant, Cell and Environment, v. 22, p. 1463-1473, 1999. DOI: 10.1046/j.13653040.1999.00514.x. 